NASA Technical Memorandum 107018

AIAA-95-2513

\title{
Advanced Propulsion for Geostationary Orbit Insertion and North-South Station Keeping
}

Steven R. Oleson and Roger M. Myers

NYMA, Inc.

Brook Park, Ohio

Craig A. Kluever

University of Missouri-Columbia/Kansas City

Kansas City, Missouri

John P. Riehl and Francis M. Curran

Lewis Research Center

Cleveland, Ohio

Prepared for the

31st Joint Propulsion Conference and Exhibit cosponsored by AIAA, ASME, SAE and ASEE San Diego, California, July 10-12, 1995

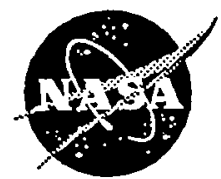

National Aeronautics and Space Administration

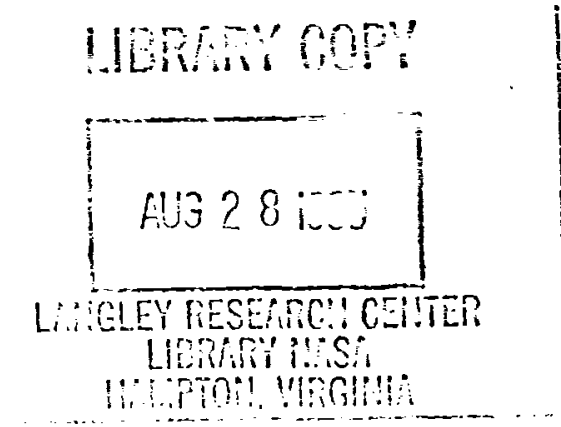




$$
\checkmark
$$

,

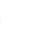




\title{
ADVANCED PROPULSION \\ FOR GEOSTATIONARY ORBIT INSERTION AND NORTH-SOUTH STATION KEEPING
}

\author{
Steven R. Oleson and Roger M. Myers \\ Nyma Inc. \\ NASA Lewis Research Center \\ Brookpark, OH 44142 \\ Craig A. Kluever \\ University of Missouri-Columbia/Kansas City \\ Kansas City, Missouri 64110 \\ John P. Riehl and Francis M. Curran \\ NASA Lewis Research Center \\ Cleveland, OH 44135
}

\begin{abstract}
Solar Electric Propulsion (SEP) technology is currently being used for geostationary satellite station keeping to increase payload mass. Analyses show that advanced electric propulsion technologies can be used to obtain additional increases in payload mass by using these same technologies to perform part of the orbit transfer. In this work three electric propulsion technologies are examined at two power levels for an Atlas IIAS class spacecraft. The on-board chemical propulsion apogee engine fuel is reduced in this analysis to allow the use of electric propulsion. A numerical optimizer is used to determine the chemical burns which will minimize the electric propulsion transfer time. Results show that for a $1550 \mathrm{~kg}$ Atlas IIAS class payload, increases in net mass (geostationary satellite mass less wet propulsion system mass) of 150 to $800 \mathrm{~kg}$ are possible using electric propulsion for station keeping, advanced chemical engines for part of the transfer and electric propulsion for the remainder of the transfer. Trip times are between one and four months.
\end{abstract}

\section{INTRODUCTION}

Solar Electric Propulsion (SEP) is already being used for station keeping of geostationary satellites, most notably hydrazine arcjets on AT\&T's Telstar 4 and SPT-100 Hall thrusters on the Russian GALS spacecraft. ${ }^{1}$ The next step in the development of electric propulsion systems is to use these types of thrusters to contribute to placing the spacecraft into geostationary orbit. For a given launch vehicle, the fuel mass savings could then be directly used to increase the payload, for instance, the number of communication transponders. Even a small increase in mass might have large revenue impacts.

The current trend for geostationary spacecraft is towards longer lifetimes, increased masses, higher powers, and increased service bandwidth. The Intelsat series of satellites present a good example of these trends. I Intelsat 1 and 2, launched during the late sixties, had lifetimes under four years. Intelsats 4 and 5 had seven year design lifetimes. Intelsat 7 had full capacity design lifetime of ten years with propellant for 15 years. The planned Intelsat 8/8A series lifetime is $14-18$ years using $\mathrm{N}_{2} \mathrm{H}_{4}$ arcjets for station keeping. These results indicate a continuing trend toward longer lifetimes, thus a 15 year lifetime is assumed in these analyses. Satellite masses, and the launch vehicles to deliver them, have also grown. Early Intelsats were well under $1000 \mathrm{~kg}$ dry mass. The planned Intelsat $8 / 8 \mathrm{~A}$ series will have a $1530 \mathrm{~kg}$ dry mass. End-of-life (EOL) power levels have increased from hundreds of watts for Intelsats 1 to 4 , to over $5 \mathrm{~kW}$ for Intelsat $7 \mathrm{~A}$. Intelsat $8 / 8 \mathrm{~A}$ will use the Martin Marietta Astro Space Series 7000 which has a beginning of life (BOL) power level over $7 \mathrm{~kW}$. Finally, communication bandwidths on Intelsat spacecraft have increased from 50 $\mathrm{MHz}$ on Intelsat 1 to $2856 \mathrm{MHz}$ on the planned Intelsat $8 / 8 \mathrm{~A}$ series. These continuing trends toward larger, more capable, longer life and higher power spacecraft were used to select the spacecraft characteristics in this study. Higher power spacecraft permit expansion of the use of electric propulsion systems beyond the already demonstrated station keeping function to encompass a portion of the orbit transfer mission. Successful implementation of advanced propulsion systems will enable continued growth of geostationary satellite capability without requiring growth in spacecraft mass or launch vehicle and will permit continued expansion of communications capability.

Studies by various authors have shown the net mass benefits of using electric propulsion for transfer from various high Earth orbits 2,3 ,Appendix in order to avoid the long trip times and Van Allen belt radiation damage of low Earth orbit (LEO) to geostationary Earth orbit (GEO) transfers using electric propulsion. 4,5 However, none of 
these starting orbits were found optimally as is possible with SECKSPOT. This paper describes the mission analyses, propulsion options, and the results for the three electric propulsion options.

The purpose of this paper is to show the performance advantages of advanced propulsion technologies for nearterm geostationary missions. This study evaluated the mass impact of replacing some portion of a geostationary spacecraft's chemical apogee propulsion system with either an $\mathrm{N}_{2} \mathrm{H}_{4}$ arcjet system, a Hall thruster system, or a xenon ion system with the electric system also performing fifteen years of station keeping. The analyses used conservative assumptions for these propulsion systems in order to make the results applicable to near-term missions. While an Atlas IIAS class spacecraft was assumed for this analysis, the advantage should be applicable to all launch vehicles. Two payload power levels, $10 \mathrm{~kW}$ and $15 \mathrm{~kW}$, were assumed to be available for the electric propulsion orbit transfer. The numerical optimization program Solar Electric Control Knob Steering Program for Optimal Trajectory (SECKSPOT) ${ }^{6}$ was used to identify the chemical burns of the Centaur upper stage and on-board propulsion system to minimize the electric propulsion transfer time.

\section{MISSION ANALYSIS, OPTIONS AND ASSUMPTIONS}

\section{Mission Analysis}

The approach is to utilize the numerical optimizer SECKSPOT with its option to perform optimal impulsive stage analysis to minimize the SEP transfer time. All that is required for the high thrust portion of the program is a final mass for this portion of the mission and an initial impulsive $\Delta \mathrm{V}$. The final mass of the impulsive portion is the starting mass for the SEP mission. The $\Delta V$ is the velocity or energy change required for an orbit transfer. Impulsive $\Delta \mathrm{V}$ assumes an instantaneous burn and is assumed for all the chemical propulsion burns in these analyses. The SEP transfer mission $\Delta V s$ differ from impulsive due to gravity losses associated with constant thrusting and nontangential steering. 7

The launch vehicle assumed for this analysis is the Atlas IIAS with the large payload fairing. ${ }^{8}$ After liftoff the Centaur upper stage uses a portion of its fuel to place the payload satellite, including the necessary on-board propulsion systems to achieve geostationary orbit, into an assumed low $185 \mathrm{~km}$ altitude circular parking orbit. While Atlas launch vehicles sometimes use elliptical parking orbits in order to optimize the perigee burn, the high thrust option of the SECKSPOT program is currently limited to circular starting orbits ${ }^{8}$.
After reaching parking orbit the Centaur stage still carries approximately $4400 \mathrm{~kg}$ of fuel which is normally used to place the payload spacecraft into geostationary transfer orbit (GTO). The GTO assumed in this analysis has a perigee altitude of $185 \mathrm{~km}$ and an apogee altitude of $35785.5 \mathrm{~km}$. The Centaur specific impulse $\left(I_{\mathrm{sp}}\right)$ is assumed to be $451.5 \mathrm{~s}$. The starting mass in the parking orbit is $10,240 \mathrm{~kg}$ which includes the spacecraft, on-board propulsion systems, and the partially fueled Centaur stage. ${ }^{9}$

The mission cases where the electric propulsion system performs only the station keeping function use the Centaur stage to place them into GTO and the on-board chemical system to insert them into geostationary orbit. The mission cases where a portion of the geostationary orbit insertion is performed by the on-board electric propulsion system use the remaining Centaur stage fuel and the available on-board chemical fuel in an optimal one or two burn transfer to an optimal SEP starting orbit as shown in Figure 1. The Centaur portion of this transfer is not necessarily to GTO.

The SECKSPOT program determines the required one or two impulsive burns with the allotted $\Delta \mathrm{V}$ to reach an SEP starting orbit which minimizes the SEP trip time. This SEP starting orbit can have any perigee, apogee, and inclination combination which is achievable with the given impulsive $\Delta \mathrm{V}$. (The Appendix contains an analytic analysis where the first burn is to GTO and the second burn changes inclination and raises perigee.) This $\Delta \mathrm{V}$ is the sum of the remaining $\Delta \mathrm{V}$ capability of the Centaur stage and some portion of the on-board apogee $\Delta \mathrm{V}$ normally carried. This on-board portion is varied from $1800 \mathrm{~m} / \mathrm{s}$ to $0 \mathrm{~m} / \mathrm{s}$ to show the trade between increased net mass and increased trip time. To illustrate these trades, Figure 2 shows a variation between the on-board chemical $\Delta \mathrm{V}$ and the transfer SEP $\Delta \mathrm{V}$ for a case using $30-\mathrm{cm}$ thrusters. Note that the Centaur $\Delta V$ is constant while the on-board chemical $\Delta \mathrm{V}$ is reduced in increments of 100 $\mathrm{m} / \mathrm{s}$. The required SEP $\triangle \mathrm{V}$ from SECKSPOT to replace the on-board chemical $\Delta V$ is greater due to gravity losses. This required SEP $\Delta V$ is further discussed in the results section. The mission where the geostationary insertion is performed solely by the on-board chemical propulsion system, case 20 , requires a chemical system $\Delta \mathrm{V}$ of 1805 $\mathrm{m} / \mathrm{s}$. The mass of the satellite after all the allotted chemical fuel is used and the dry $2180 \mathrm{~kg}$ Centaur is separated is assumed to be the starting SEP phase mass. 9

The SEP phase optimization includes the impacts of shading, J2 (Earth oblateness), and solar array degradation due to Van Allen belt radiation. The SEP system parameters of initial power level, $I_{s p}$, and efficiency are 
fixed in the SECKSPOT program. The SECKSPOT program assumes constant thrusting except while the spacecraft is in shade. SECKSPOT finds the optimal steering for the minimum time trajectory. This minimum time trajectory closely estimates maximum delivered mass since, in order to minimize time for a constant thrusting transfer, SEP $\Delta \mathrm{V}$, and thus fuel mass, is minimized.

The impact of power degradation on the trip time causes SECKSPOT to minimize time spent in the Van Allen belts. As power is degraded, SECKSPOT throttles the thrusters accordingly while maintaining the same $\mathrm{I}_{\mathrm{sp}}$ and efficiency. While thruster performance normally varies as a function of power level this effect is neglected in this work. This SECKSPOT/SEP system modelling limitation is negligible for the desired short transfer time trajectories since the power degradation is negligible. The impacts of non-optimal steering and guidance, navigation, and attitude control limitations are not considered here. The impacts of these issues are typically minor.

In addition to the transfer, fifteen years of north/south station keeping (NSSK) are assumed for all cases ${ }^{1}$. While the yearly $\Delta \mathrm{V}$ varies with satellite station longitude, 45.37 $\mathrm{m} / \mathrm{s}$ is chosen as representative. 10 The daily station keeping burn time using electric propulsion is on the order of tens of minutes. The cosine losses encountered by not completing the whole bum instantaneously at the orbit node are small and neglected. East/west station keeping requirements are an order-of-magnitude smaller than NSSK requirements and are neglected in these analyses.

\section{SYSTEM ASSUMPTIONS AND MODELING}

\section{On-Board Chemical Propulsion System}

For mission scenarios requiring an on-board chemical propulsion system for all or part of the orbit insertion, an advanced $328 \mathrm{~s} \mathrm{I}_{\mathrm{sp}}$ bipropellant system is assumed. 11 A $314.5 \mathrm{~s} \mathrm{I}_{\mathrm{Sp}}$ system is assumed only for the state-of-art (SOA) case. Both systems have a fixed dry mass of 23 $\mathrm{kg}$ and a tankage fraction of 0.08 . The advanced chemical system is deleted from the spacecraft for those missions where the SEP system takes over directly from the Centaur stage.

\section{On-Board Electric Propulsion System}

For mission scenarios using on-board SEP for NSSK and, in some cases, orbit insertion functions, the following technologies are considered: SOA $1.8 \mathrm{~kW} \mathrm{~N}_{2} \mathrm{H}_{4}$ arcjets ${ }^{12}$ for NSSK function only, two advanced $2.17 \mathrm{~kW} \mathrm{~N} \mathrm{H}_{4}$ arcjets, ${ }^{13} 1.5 \mathrm{~kW}$ xenon Hall thrusters ${ }^{14}$ and $2.5 \mathrm{~kW}$ $30 \mathrm{~cm}$ xenon ion thrusters. ${ }^{13}$. The power given is the power into the power processing unit (PPU). All thruster parameters are shown in Table 1. SOA arcjets are produced by the Olin Aerospace and currently in use on the Telstar 4 spacecraft. Advanced arcjets are under development by the NASA on-board propulsion program. Hall thrusters, which were developed in Russia, are being qualified for western spacecraft by Space Systems Loral. The $30 \mathrm{~cm}$ xenon ion thruster technology is being developed under the NASA Solar electric propulsion Technology Applications Readiness (NSTAR) program. Throughout this analysis the same propulsion technology is used for both transfer and NSSK functions -- no mixing of propulsion technologies is considered.

For the orbit insertion function, the assumed thruster $\mathrm{I}_{\mathrm{sp}} \mathrm{s}$ are: 600 s for the advanced arcjet, 650 s for the advanced+ arcjet, 1600s for the Hall thruster, and 3160 s for the ion thruster. The overall PPU/thruster efficiencies regardless of mission function are: 0.33 for the SOA arcjet, 0.33 for the advanced arcjet, 0.31 for the advanced+ arcjet, 0.45 for the xenon Hall thruster, and 0.60 for the xenon ion thruster.

Each thruster unit includes structure, gimbal (except arcjet SOA) and controller; resulting in masses of $1.86 \mathrm{~kg}$ for the SOA arcjet, $2.17 \mathrm{~kg}$ for the advanced and advanced+ arcjets, $9.33 \mathrm{~kg}$ for the Hall thrusters, and $13.83 \mathrm{~kg}$ for the ion thrusters. Each PPU unit includes cabling and thermal system; resulting in power densities of 6.08 $\mathrm{kg} / \mathrm{kW}$ for the SOA arcjet, $\quad 6.08 \mathrm{~kg} / \mathrm{kW}$ for the advanced and advanced+arcjets, $9 \mathrm{~kg} / \mathrm{kW}$ for the Hall thrusters, and $9.10 \mathrm{~kg} / \mathrm{kW}$ for the ion thrusters. A tankage fraction of 0.07 was used for arcjets and 0.15 for the Hall and ion thrusters. Thruster lifetime is also considered and extra thrusters are added when necessary. Assumed thruster lifetimes are 1000 hours for the arcjet SOA, 1500 hours for the advanced and advanced+ arcjets, 4000 hours for the Hall thrusters, and 8000 hours for the ion thrusters. PPU lifetime was assumed adequate for both the transfer and station keeping missions.

Fifteen years of north/south spacecraft station keeping is performed by four thrusters, one pair placed on the north face and the other on the south face as shown in Figure 3. These thruster pairs are canted $17^{\circ}, 45^{\circ}$, and $30^{\circ}$ for the arcjets, Hall thrusters, and ion thrusters, respectively, from the vertical to minimize plume interaction with the array. The equivalent NSSK thruster $I_{s p}$ is adjusted for the thruster cant cosine loss as follows: $478 \mathrm{~s}$ for the SOA NSSK arcjet, 574s for the advanced arcjet, $622 \mathrm{~s}$ for the advanced+ arcjet, 1131s for the Hall thruster, and 2736s for the ion thruster. To perform the north/south station keeping either the south or north pair is fired about the appropriate orbit node on the order of tens of minutes. If one thruster fails the opposite set are tasked with all 
NSSK burns. Four PPUs support the four NSSK thrusters.

Additional thrusters are added for performing the SEP transfer mission. $10 \mathrm{~kW}$ and $15 \mathrm{~kW}$ available power levels are assumed (see power section). Thrusters are added for the transfer mission to take advantage of the available power. Consequently, the $10 \mathrm{~kW}$ spacecraft uses either four arcjets, six Hall thrusters, or four ion thrusters. The $15 \mathrm{~kW}$ spacecraft uses either six arcjets, ten Hall thrusters, or six ion thrusters. Due to the assumed available power levels not all of the power available can be used by the arcjet thrusters. As mentioned previously, the thrusters are assumed identical to the NSSK thrusters except they are placed about the chemical thruster on the aft portion of the spacecraft as shown in Figure 3. The transfer thrusters use the available four NSSK PPUs and have additional PPUs added for extra thrusters, for example, the six Hall thrusters have two PPUs added to the spacecraft. During SEP transfer all the transfer thrusters are firing except in shade. Additional thrusters for redundancy were not added.

\section{Power System}

The GaAs solar arrays which provide payload power in geostationary orbit are assumed to. provide the $10 \mathrm{~kW}$ or $15 \mathrm{~kW}$ for the thruster operation during the SEP orbit transfer since the payload is inactive during this phase. These power levels were chosen as representative of next generation power levels for geostationary communication satellites. ${ }^{1}$ The battery system is assumed power dual NSSK thruster operation while the payload uses direct solar array power as suggested by Free. 15 Extra batteries may be required to support the increase in charge/discharge cycling, but this mass is not determined here. The arrays are assumed to have an equivalent layer of 6 mils fused silica shielding on both sides of the solar array for radiation protection. 10 Since the array is resident on the spacecraft for payload use its mass is not charged to the propulsion system. However, transfer through the Van Allen belts will damage the array. This damaged array mass is charged to the propulsion system at a rate of 16.6 $\mathrm{kg} / \mathrm{kW} .16$ Thus the propulsion system is penalized for long transfers through the Van Allen Belts. While the radiation damage that may occur to the payload is not assessed here it should be less than that encountered by the array.

\section{RESULTS}

The figures of merit of the advanced propulsion systems in this study are the net mass delivered and SEP transfer time. Net mass refers to the usable satellite mass once the wet propulsion system and any damaged array are removed. The added net mass can be used for additional payload to increase revenue. Figures 4, 5, 6 and 7 exhibit the net masses versus SEP trip times. The SOA system is assumed to be a $314.5 \mathrm{~s} \mathrm{I}_{\mathrm{sp}}$ on-board chemical system which delivers the spacecraft into geostationary, and a 500s $\mathrm{I}_{\mathrm{sp}}, 1.8 \mathrm{kw}$ arcjet system which only performs the NSSK. These systems are termed the SOA technologies and both are described in the systems assumptions section. Using the same launch vehicle and Centaur stage assumptions the SOA chemical and SOA arcjet system delivered net mass is $1551 \mathrm{~kg}$. This will be referred to as the baseline-SOA case. The impact of replacing the SOA chemical system with the advanced chemical system while retaining the SOA arcjet increases the net mass to $1598 \mathrm{~kg}$, for a gain of $47 \mathrm{~kg}$, as shown in Figure 5. This $1598 \mathrm{~kg}$ net mass case is considered the baseline (and termed "baselineadvanced chemical case') for all further evaluations of the added performance of advanced electric propulsion technologies.

\section{SEP Starting Orbits}

Optimal SEP starting orbits determined by SECKSPOT for the $10 \mathrm{~kW}$ spacecraft with ion technology are shown in Figure 8. These SEP starting orbits vary little for the different SEP technologies' power levels. So Figure 8 is representative of all the results. The orbit parameters, including apogee altitude, perigee altitude, and inclination, are shown verses the on-board chemical propulsion $\Delta \mathrm{V}$ which directly relates to chemical propulsion fuel loading. Only one or two burns are allowed by the code. The three cases with $200 \mathrm{~m} / \mathrm{s}$ or less of on-board chemical fuel, or $\Delta \mathrm{V}$ capability, use only one perigee burn to lift apogee as high as possible. A slight plane change is also performed. In practice, several perigee burns might be used. Increasing the on-board chemical $\Delta \mathrm{V}$ capability above 200 $\mathrm{m} / \mathrm{s}$, up to $1800 \mathrm{~m} / \mathrm{s}$, allows an optimal two burn case where the apogee is raised above geostationary orbit altitude, the perigee is also raised, and the some portion of the plane change performed. These SEP starting orbits differ from those assumed in the Appendix which start with GTO and then change inclination/raise perigee.

By setting the apogee above and the perigee below the target orbit, SECKSPOT increases the time the spacecraft spends out of the most damaging portions of the radiation belts. The higher apogee results in a lower velocity location for plane changing. The apogee is lowered during the perigee portions of the orbit. The optimal steering determined by SECKSPOT and practical steering methods to approximate the optimal steering will be reported in further publications.

Figure 2 shows the corresponding required transfer SEP $\Delta \mathrm{V}$ for the varied on-board chemical $\Delta \mathrm{V}$ for the $10 \mathrm{~kW}$ ion class. This is again similar for all the SEP technologies. Mission case 20 represents geostationary 
insertion performed solely by the on-board chemical propulsion, and cases 1 to 18 show the trade in chemical and SEP $\Delta V$. As on-board chemical $\Delta V$ capability is replaced by SEP $\Delta V$, the total $\Delta V$ increases due to the gravity losses incurred by the constant thrusting SEP system. Case 19 shows the limit when the GTO to GEO transfer is performed completely by the SEP system and the Centaur stage. Comparing cases 19 and 20 clearly shows the increased $\Delta V$ required. However, the higher $I_{s p}$ of the SEP system more than offsets this increased $\Delta V$ by a significantly reducing the total fuel mass. This is shown by the net mass advantage in the next sections.

\section{$10 \mathrm{~kW}$ Class Spacecraft}

Figures 4 and 5 contain the results of this analysis for a $10 \mathrm{~kW}$ class spacecraft in terms of net mass versus SEP transfer time. Figure 5 shows the NSSK missions where the orbit transfer is completed by the Centaur stage and onboard chemical system and the station keeping is performed by the electric propulsion system. These NSSK only SEP missions show the net mass benefit of implementing the advanced electric propulsion technologies just for NSSK. As expected, the higher $\mathrm{I}_{\mathrm{sp}}$ systems provide a greater net mass. The advanced chemical transfer and advanced SEP NSSK systems provide an 80 to $200 \mathrm{~kg}$ increase in net mass over the baseline SOA system.

Figures 4 and 5 also show that by expanding the electric propulsion system to provide part of the transfer, even greater net mass gains may be realized. SEP transfers up to a year are shown. Performance plateaus occur when extra thrusters must be added due to lifetime considerations. This occurs, for example, for Hall thrusters at a transfer time between 210 days and 230 days, as shown in Figure 4. The initial steepness of each technology's curve is reduced somewhat for longer transfer times due to the increased rate of solar array damage (see Figure 9), which is subtracted from the net mass. This increased damage rate is due to longer exposure times in the more damaging portions of the Van Allen belts. For the shortest transfer times, where the on-board chemical system is providing most of the transfer, the radiation damage is small, and the net mass gain increases quickly as allowable SEP transfer time is relaxed. This region of slight degradation occurs for on-board chemical $\Delta V s$ above approximately $1000 \mathrm{~m} / \mathrm{s}$. For SEP transfer times below 120 days in Figure 5, the net mass gain for the arcjet technologies smooths out after about 40 days due to the appearance substantial radiation damage. Hall and ion technologies smooth out at longer transfer times due to their lower thrust but at the same point of notable radiation damage.
The net mass gains to be made with any of the advanced SEP technologies are considerable. The $600 \mathrm{~s}$ and $650 \mathrm{~s} \mathrm{I}_{\mathrm{sp}}$ arcjets provide an additional $60 \mathrm{~kg}$ and $80 \mathrm{~kg}$, respectively, of net mass over NSSK alone for a one month transfer time. The Hall and ion systems provide even greater net mass gains just performing the NSSK mission. After about 10 to 15 days transfer time both systems add even more net mass. Below this transfer time the additional equipment dry mass overwhelms the higher $I_{s p}$ advantage. These data are not shown in Figures $4-7$ for the sake of clarity. For a one month transfer time, which is roughly equivalent to a geostationary satellite's checkout time, the use of Hall thrusters or ion thrusters for part of the orbit transfer increases the satellite net mass by 110 and $120 \mathrm{~kg}$ over NSSK only, respectively. Compared to the baseline-advanced chemical case, the net mass increase is $230 \mathrm{~kg}$ with the Hall thruster and $270 \mathrm{~kg}$ with the ion thruster. These provide net mass gains of $14 \%$ for the Hall to $16 \%$ for the ion. A more appropriately powered $(\sim 2.5 \mathrm{~kW})$ Hall thruster may have an increased net mass benefit.

Allowing two months of trip time adds more net mass for all the thruster systems, with Hall and ion out-performing arcjets. The rate of net mass increase for the arcjets with transfer times greater than two months is minor, mainly due to the increasing damage to the solar array. Hall and ion thrusters add over 350 to $400 \mathrm{~kg}$, respectively, when compared to the baseline-advanced chemical case. At three and four month transfer times the ion thrusters add over 550 and $650 \mathrm{~kg}$ for a substantial $34 \%$ to $40 \%$ increase over the baseline-advanced chemical case. The cost of these transfer times is not considered here.

Not only can net mass be significantly increased, but spacecraft growth during design and production can easily be handled merely by removing some of the on-board chemical propellant and adding some SEP propellant. Thus by designing the SEP fuel tanks for extra fuel, substantial net mass flexibility can be attained at the cost of some extra tankage.

\section{$15 \mathrm{~kW}$ Class Spacecraft}

Results for the $15 \mathrm{~kW}$ spacecraft, shown in Figures 6 and 7 , are similar to those of the $10 \mathrm{~kW}$ spacecraft. Faster transfer times due to higher SEP powers are offset by additional thrusters and PPUs. The NSSK only scenario points are identical to those of the $10 \mathrm{~kW}$ spacecraft since the additional power is not used for the NSSK system.

An additional 60 to $90 \mathrm{~kg}$ is provided compared to the baseline-advanced chemical system by adding six transfer $600 \mathrm{~s}$ and $650 \mathrm{~s} \mathrm{I}_{\mathrm{sp}}$ arcjet thrusters and two PPUs, respectively, for a two week transfer time. Between 100 
and $140 \mathrm{~kg}$ can be added if the transfer time is set to one month. Using a Hall system yields an additional 250-440 $\mathrm{kg}$ and the ion system yields $290-500 \mathrm{~kg}$ over the baselineadvanced chemical system for one and two month trip times, respectively. Thus the $-30 \%$ net mass gain is obtained in two months for the $15 \mathrm{~kW}$ class spacecraft as compared to three with the $10 \mathrm{~kW}$ spacecraft. While greater net mass gains can be obtained for longer transfer times, increased radiation is encountered which would also have an adverse effect upon the payload.

The radiation dose encountered by the $15 \mathrm{~kW}$ spacecraft is less than that of the $10 \mathrm{~kW}$ spacecraft (Figure 10). While the shapes of damage factor are similar for the 10 $\mathrm{kW}$ and $15 \mathrm{~kW}$ spacecraft, the extent of damage is greater for the slower $10 \mathrm{~kW}$ spacecraft. As with the $10 \mathrm{~kW}$ spacecraft, the transition to significant radiation damage occurs for on-board $\Delta V \mathrm{~s}$ below $1000 \mathrm{~m} / \mathrm{s}$ for the $15 \mathrm{~kW}$ spacecraft.

\section{CONCLUSIONS}

The use of advanced on-board propulsion systems to perform both the NSSK and part of the orbit transfer was examined for GEO spacecraft. Substantial increases in net mass were obtained for moderate trip times, showing the possibility of significant payload enhancements. Upgrading to advanced on-board chemical transfer systems alone can increase the net mass by over $3 \%$. If, in addition to upgrading the advanced on-board chemical transfer system, an advanced solar electric NSSK system is utilized, an increase in net mass of as much as $13 \%$ is realized. Use of advanced SEP for a portion of the orbit transfer increases the net mass by as much as $20 \%$ to $45 \%$ for one to four month transfer times, respectively. The trip time depends on power levels, which were set to 10 or $15 \mathrm{~kW}$ in this study based on current trends in geostationary satellite technology. The use of SEP for portions of the transfer also allows spacecraft design and production mass growth by extending the transfer time.

\section{Acknowledgments}

Research for this paper was done at NASA Lewis Research Center's Advanced Space Analysis Office (Contract NAS327186). We would like to recognized Bernie Free for his continuing enthusiasm for this potential use of electric propulsion. We are indebted to Timothy Wickenheiser, Rick Burdick, and Leon Gefert for their insightful contributions to this paper.

\section{References}

1. Wilson, A., Jane's Space Directory, Tenth Edition 1994-95, 1994 Jane's Information Group Ltd., Sentinel House, Surrey, UK.

2. Caveny, L.H., Vondra, R.J. "Ion Propulsion Goals for Earth Orbit Transfer", AIAA 90-2621, 21st International Electric Propulsion Conference, July 18-20, 1990 , Orlando, FL.

3. Oleson, S.R. , Curran, F.M., Myers, R.M., "Electric Propulsion For Geostationary Orbit Insertion", NASA TM-106942.

4. Porte, F., et al., "Benefits of Electric Propulsion for Orbit Injection of Communication Spacecraft", AIAA-921955, 14th ALAA International Communication Satellite Systems Conference, March 22-26, 1992, Washington, D.C.

5. Oleson, S.R. "Influence of Power System Technology of Electric Propulsion Missions", CR-195419, NASA Lewis Research Center, January 1995.

6. Sackett, L.L., et al., "Solar Electric Geocentric Transfer with Attitude Constraints: Analysis", NASA CR-134927, August, 1975.

7. Edelbaum, T.N. "Propulsion Requirements for Controllable Satellites", ARS Journal, 31: 1079-1089. August 1961.

8. Atlas Mission Planner's Guide, Volume 1, Dec. 9, 1993, General Dynamics Commercial Launch Services, San Diego, CA

9. Armstrong, R.C. , Duffey, J., Transportation Systems Data Book, DCN 1-4-PP-02473, NASA Marshall Space Flight Center, AL.

10. Agrawal, B.N. Design of Geosynchronous Spacecraft. Prentice-Hall, Inc. Englewood Cliffs, NJ.

11. Myers, R.M., et al., "Small Satellite Propulsion Options", NASA TM-106701, AIAA-94-2997, June 1994. 12. G.L. Bennett, et al., "An Overview of NASA's Electric Propulsion Program”,IEPC-93-006, Sept 1993. 13. Rawlin, V.K., Majcher, G.A., "Mass Comparisons of Electric Propulsion Systems for NSSK of Geosynchronous Spacecraft", NASA TM-105153.

14. Sankovic, J., Hamley, J., Haag, T. , "Performance Evaluation of the Russian SPT-100 Thruster at NASA LeRC", IEPC Paper 93-094;23rd International Electric Propulsion Conference, Sept. 13-16, 1993.

15. Free, B.A. "North-South Stationkeeping with Electric Propulsion Using Onboard Battery Power", COMSAT Laboratories, 1980

16. Pollard, J.E., et al, "Electric Propulsion Flight Experience and Technology Readiness", Paper AIAA 932221, 29th Joint Propulsion Conference, June 28-30, Monterey, CA. 

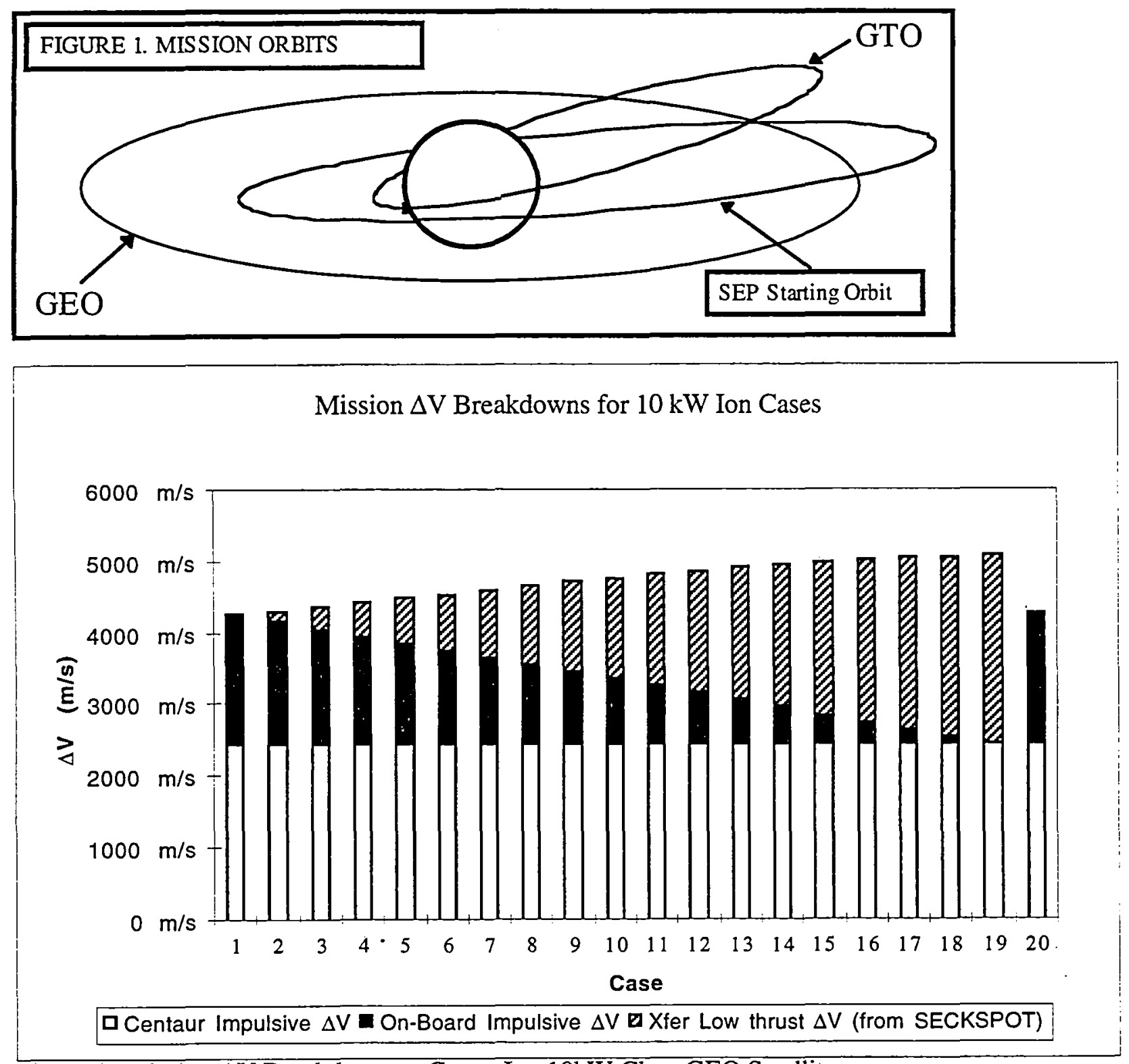

Figure 2. Mission $\Delta V$ Breakdown vs Case - Ion 10kW Class GEO Satellite 
Table 1. SEP Propulsion System Parameters

\begin{tabular}{|c|c|c|c|c|}
\hline $\begin{array}{c}\text { Propulsion System } \\
\text { Parameters }\end{array}$ & $\mathrm{SOA} \mathrm{N}_{2} \mathrm{H}_{4}$ Arcjet & $\begin{array}{c}\text { Advanced, Advanced }+ \\
\mathrm{N}_{2} \mathrm{H}_{4} \text { Arcjet } \\
\end{array}$ & Xenon Hall Thruster & Xenon Ion Thruster \\
\hline $\begin{array}{c}\text { Desired PPU Input Power } \\
\text { Level }\end{array}$ & $1.8 \mathrm{~kW}$ & $2.4 \mathrm{~kW}$ & $1.5 \mathrm{~kW}$ & $2.5 \mathrm{~kW}$ \\
\hline Isp & $500 \mathrm{~s}$ & $600 \mathrm{~s}, 650 \mathrm{~s}$ & $1600 \mathrm{~s}$ & $3160 \mathrm{~s}$ \\
\hline $\begin{array}{c}\text { Overall Efficiency (PPU \& } \\
\text { Thruster) }\end{array}$ & 0.33 & $0.33,0.31$ & 0.45 & 0.60 \\
\hline Tankage & $7 \%$ & $7 \%$ & $15 \%$ & $15 \%$ \\
\hline Life at Power Level & 1,000 hours & 1,500 hours & 4,000 hours & 8,000 hours \\
\hline Cant Angle for NSSK & $17^{\circ}$ & $17^{\circ}$ & $45^{\circ}$ & $30^{\circ}$ \\
\hline Equivalent Cant Isp & $478 \mathrm{~s}$ & $574 \mathrm{~s}, 622 \mathrm{~s}$ & $1131 \mathrm{~s}$ & $2736 \mathrm{~s}$ \\
\hline \multicolumn{5}{|l|}{ Masses: } \\
\hline Thruster & $1 \mathrm{~kg}$ & $1 \mathrm{~kg}$ & $5 \mathrm{~kg}$ & $7 \mathrm{~kg}$ \\
\hline Gimbals & $34 \%$ of Thruster & $34 \%$ of Thruster & $34 \%$ of Thruster & $34 \%$ of Thruster \\
\hline Support & $\begin{array}{c}31 \% \text { of Gimbals } \\
\& \text { Thrusters }\end{array}$ & $\begin{array}{c}31 \% \text { of Gimbals } \\
\& \text { Thrusters }\end{array}$ & $\begin{array}{c}31 \% \text { of Gimbals } \\
\& \text { Thrusters }\end{array}$ & $\begin{array}{c}31 \% \text { of Gimbals } \\
\& \text { Thrusters }\end{array}$ \\
\hline Controller & $0.55 \mathrm{~kg} /$ Thruster & $0.55 \mathrm{~kg} /$ Thruster & $0.55 \mathrm{~kg} /$ Thruster & $1.55 \mathrm{~kg} /$ Thruster \\
\hline $\begin{array}{c}\text { Total Thruster + Gimbal }+ \\
\text { Support }+ \text { Controller }\end{array}$ & $2.3 \mathrm{~kg} /$ thruster & $2.3 \mathrm{~kg} /$ thruster & $9.3 \mathrm{~kg} /$ thruster & $13.8 \mathrm{~kg} / \mathrm{thruster}$ \\
\hline Feed System & $0.8 \mathrm{~kg} / \mathrm{kWe}$ & $0.8 \mathrm{~kg} / \mathrm{kWe}$ & $1.5 \mathrm{~kg} / \mathrm{kWe}$ & $1.5 \mathrm{~kg} / \mathrm{kWe}$ \\
\hline $\mathrm{PPU}$ & $2.4 \mathrm{~kg} / \mathrm{kWe}$ & $2.4 \mathrm{~kg} / \mathrm{kWe}$ & $4.7 \mathrm{~kg} / \mathrm{kWe}$ & $4.8 \mathrm{~kg} / \mathrm{kWe}$ \\
\hline Cabling & $0.4 \mathrm{~kg} / \mathrm{kWe}$ & $0.4 \mathrm{~kg} / \mathrm{kWe}$ & $0.4 \mathrm{~kg} / \mathrm{kWe}$ & $0.4 \mathrm{~kg} / \mathrm{kWe}$ \\
\hline Thermal Sys. (92\% PPU) & $31 \mathrm{~kg} / \mathrm{kWt}$-disp. & $31 \mathrm{~kg} / \mathrm{kWt}$-disp. & $31 \mathrm{~kg} / \mathrm{kWt}$-disp. & $31 \mathrm{~kg} / \mathrm{kWt}$-disp. \\
\hline $\begin{array}{l}\text { Total PPU + Feed + } \\
\text { Cabling + Thermal }\end{array}$ & $6.1 \mathrm{~kg} / \mathrm{kWe}$ & $6.1 \mathrm{~kg} / \mathrm{kWe}$ & $9.1 \mathrm{~kg} / \mathrm{kWe}$ & $9.2 \mathrm{~kg} / \mathrm{kWe}$ \\
\hline
\end{tabular}

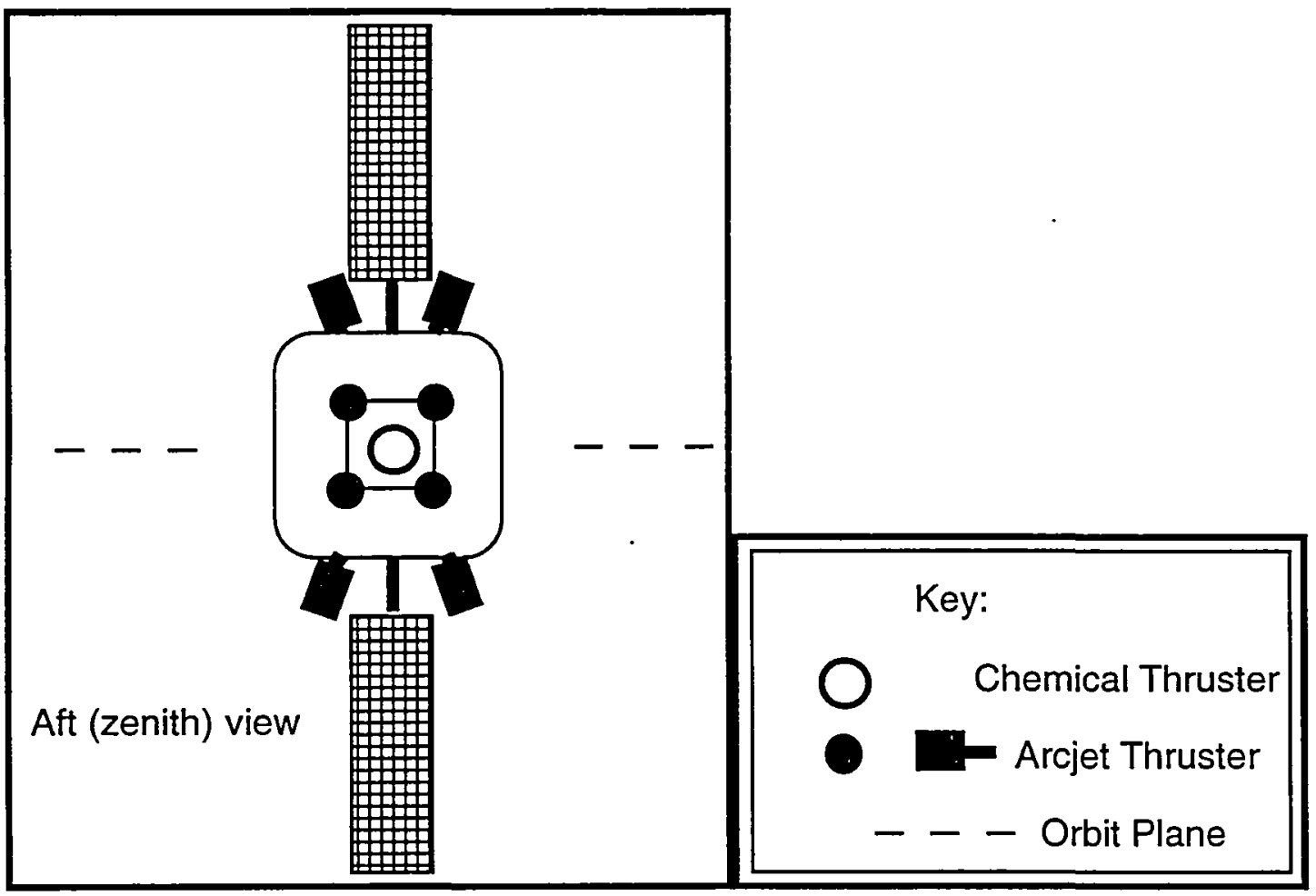

Figure 3. Potential Thruster Configuration 


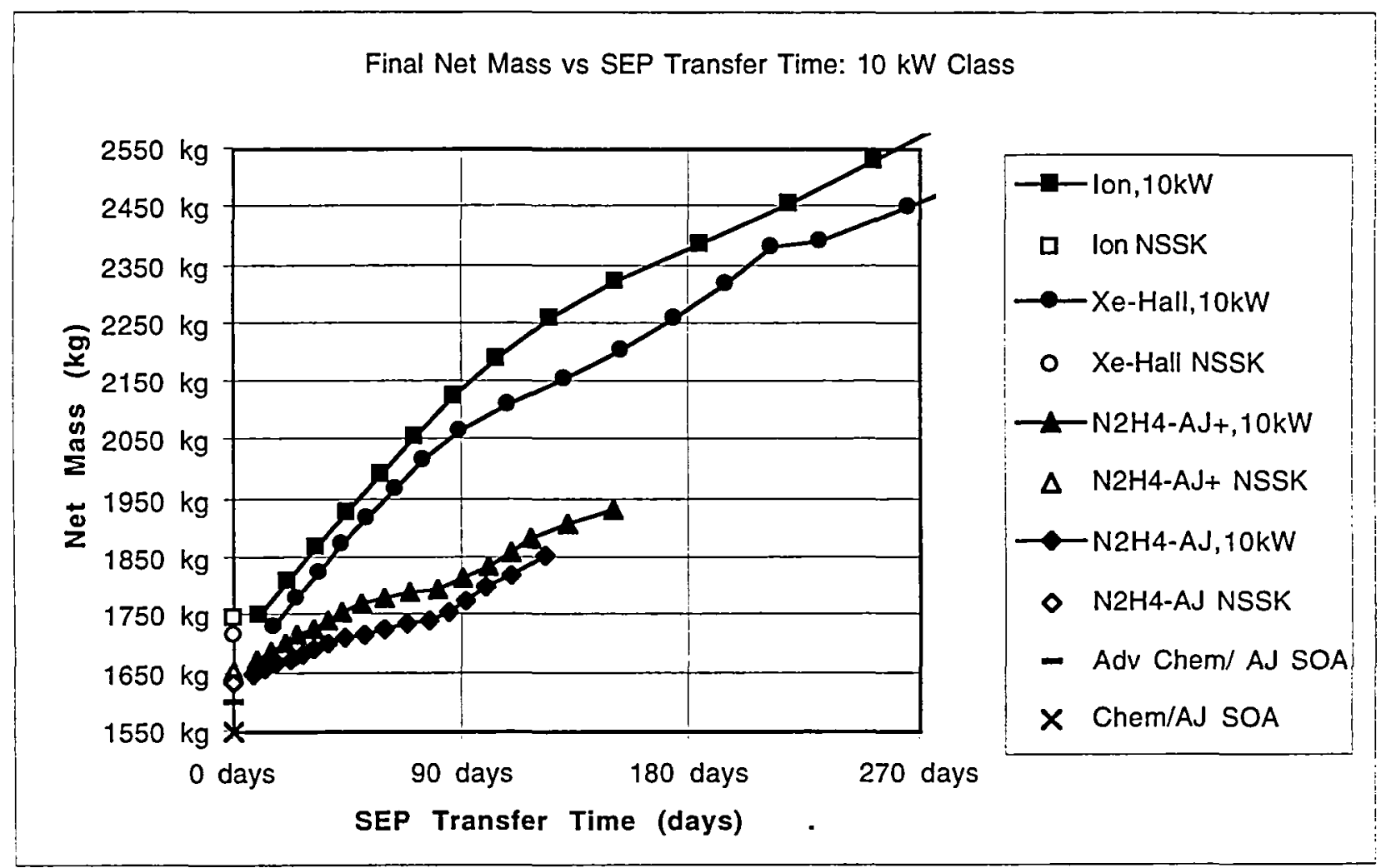

Figure 4. Final Net Mass vs. SEP Transfer Time for a $10 \mathrm{~kW}$ Class GEO Satellite

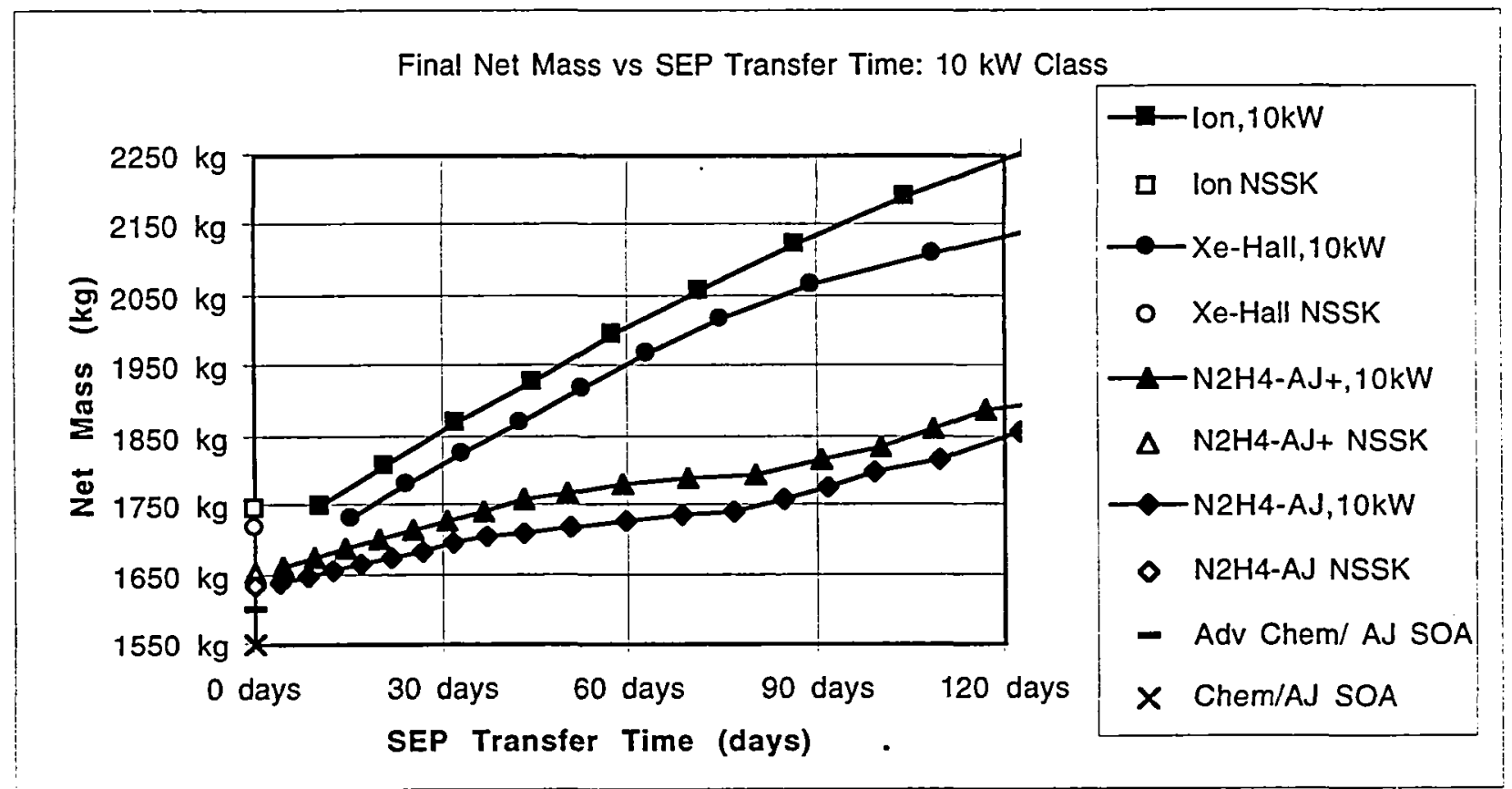

Figure 5. Final Net Mass vs. SEP 3 month or less Transfer Time- $10 \mathrm{~kW}$ Class GEO Satellite 


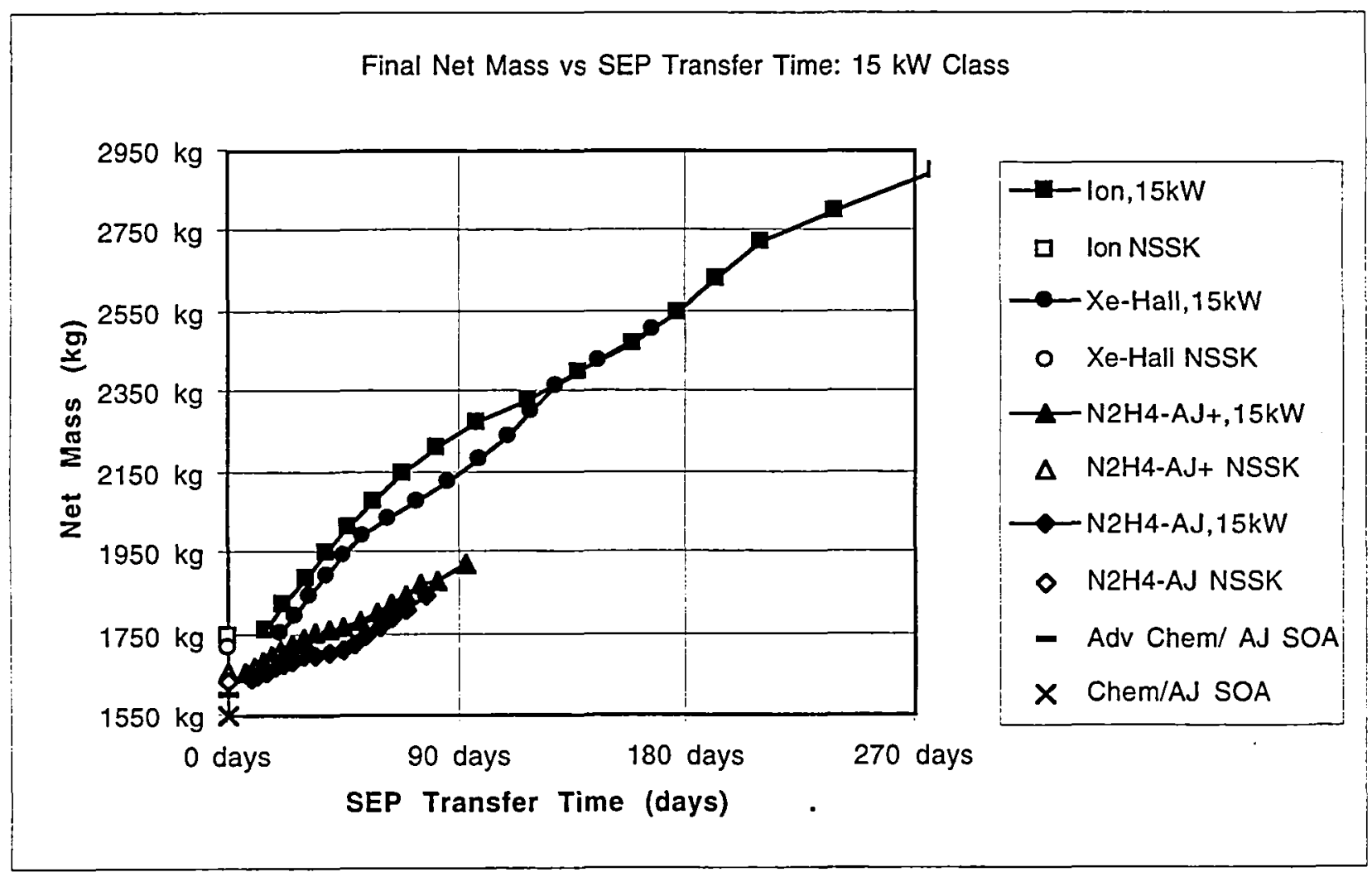

Figure 6. Final Net Mass vs. SEP Transfer Time for a $15 \mathrm{~kW}$ Class GEO Satellite

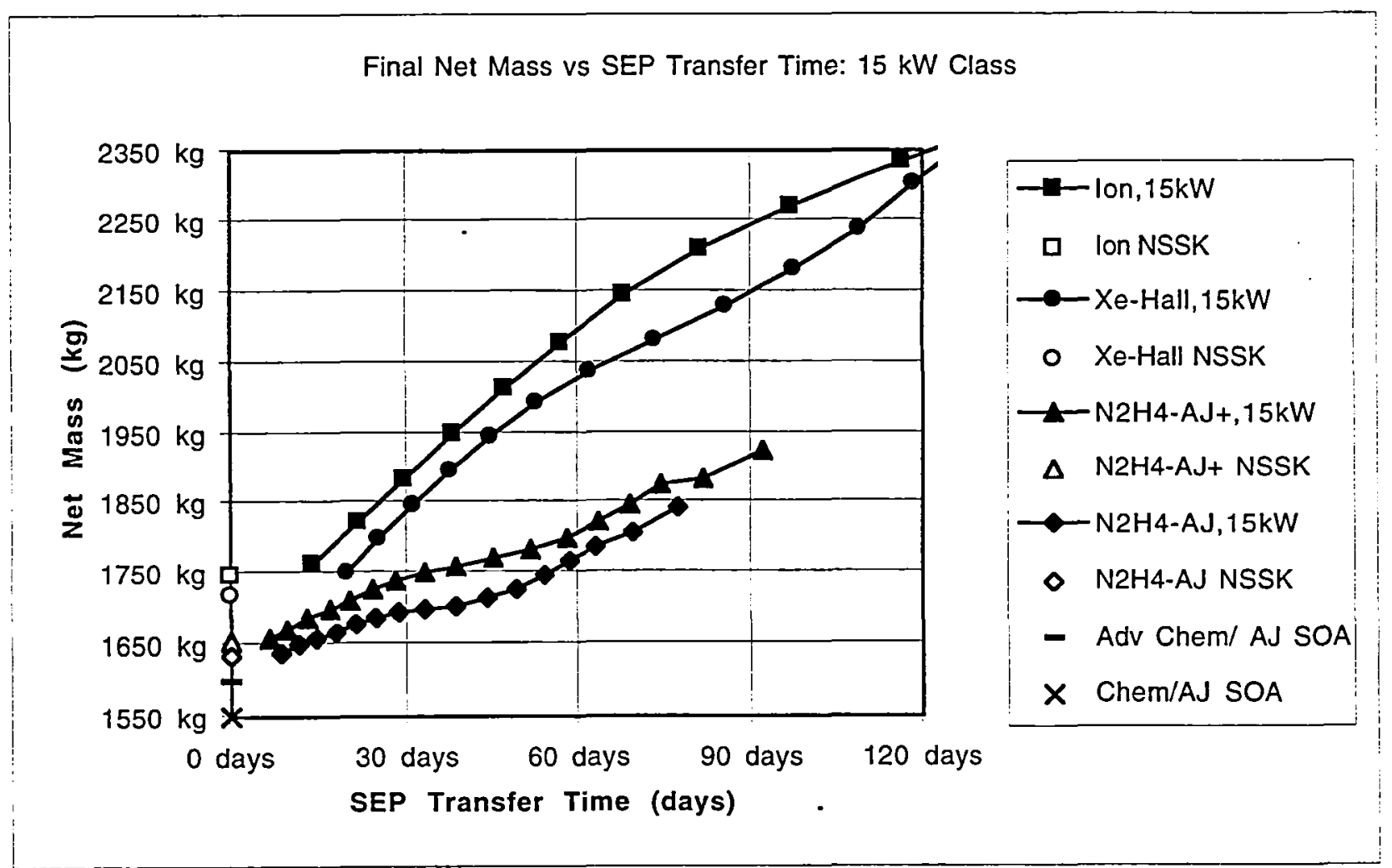

Figure 7. Final Net Mass vs. SEP 3 month. or less Transfer Time- $15 \mathrm{~kW}$ Class GEO Satellite 


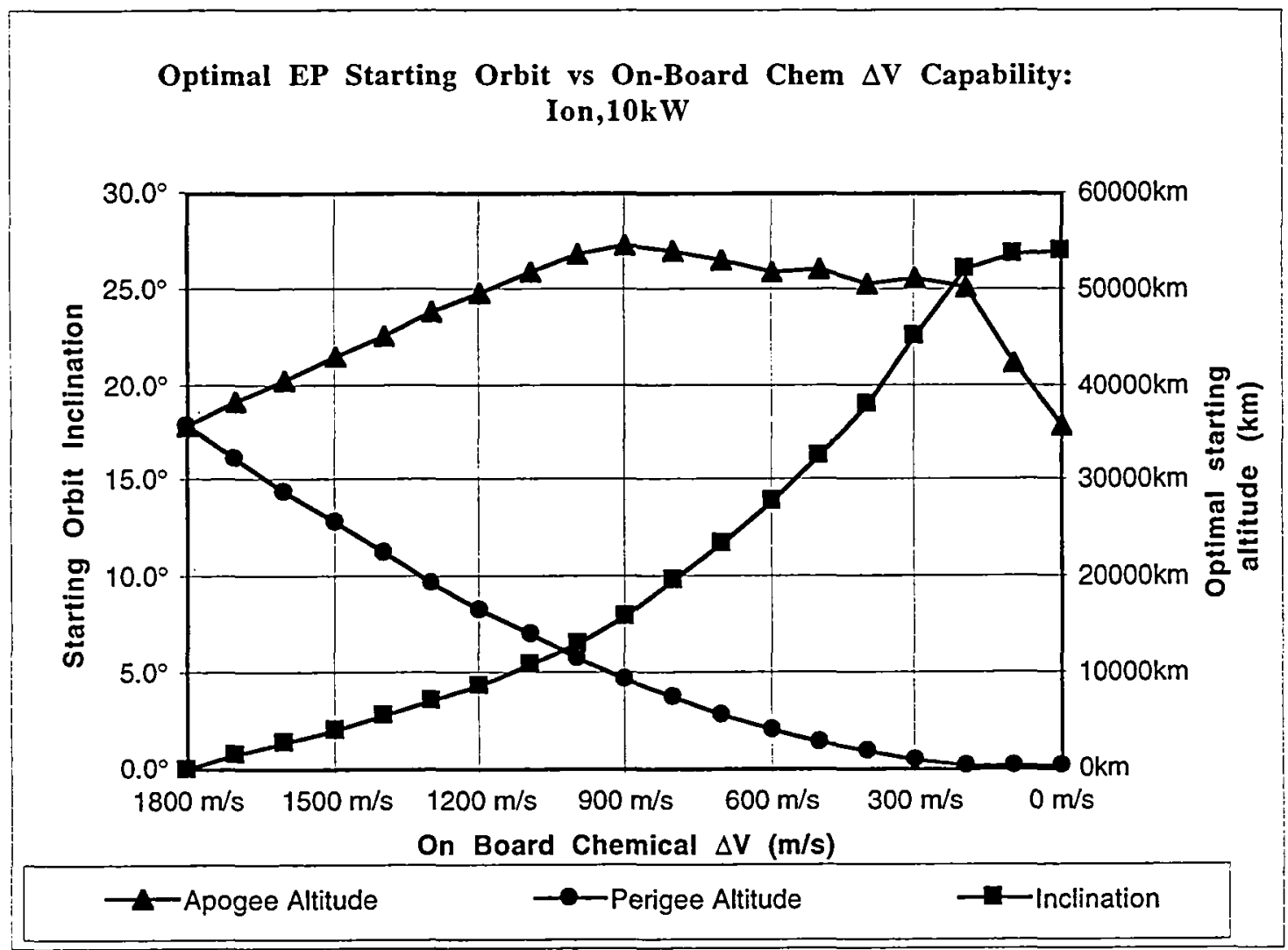

Figure 8. Optimal SEP Starting Orbit vs. On-Board Chemical $\Delta \mathrm{V}$ - Ion 10kW Class GEO Satellite

This space left intentionally blank 


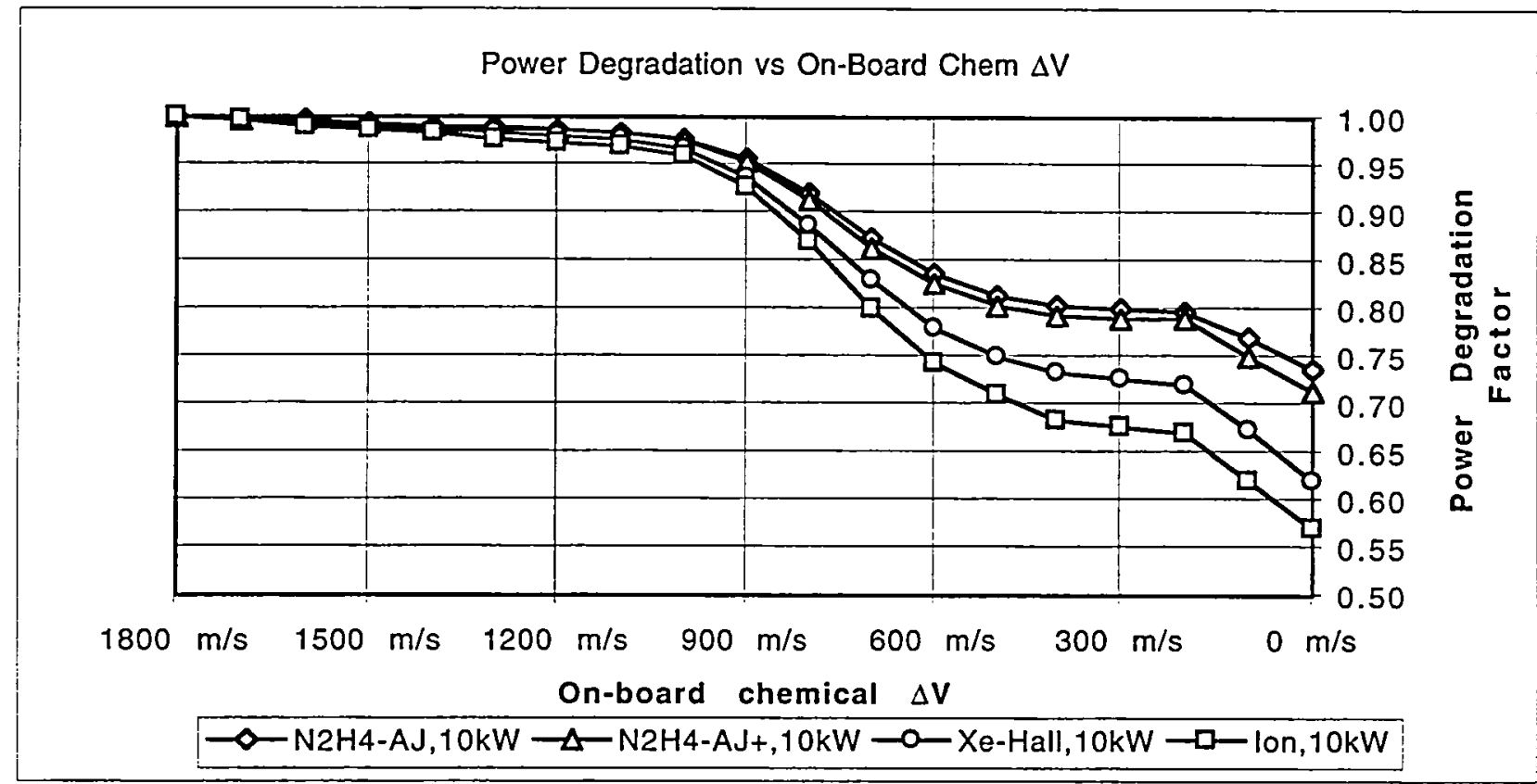

Figure 9. Power Degradation Factor vs. On-Board Chemical $\Delta \mathrm{V}-10 \mathrm{~kW}$ Class GEO Satellite

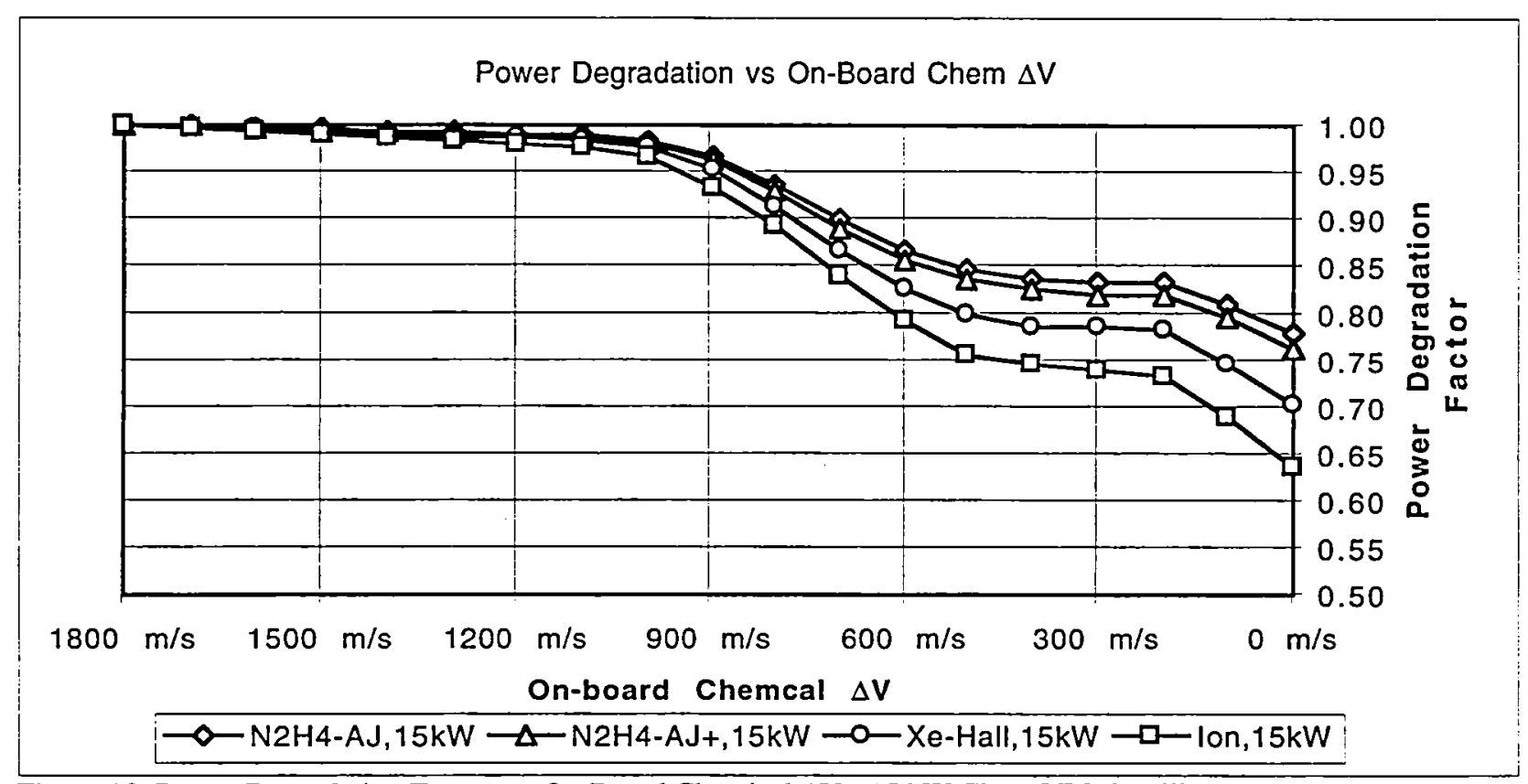

Figure 10. Power Degradation Factor vs. On-Board Chemical $\Delta V-15 \mathrm{~kW}$ Class GEO Satellite 


\section{Appendix:}

\section{Analytic Trades for SEP Transfers from Super GTO to GEO}

\author{
CRAIG A. KLUEVER
}

\section{INTRODUCTION}

The payload benefits associated with the use of electric propulsion for performing near-Earth orbit transfers has been investigated by several authors ${ }^{1 \cdot 3}$. However, the utilization of a lowthrust engine for transferring a payload from low Earth orbit (LEO) to geosynchronous orbit (GEO) is a far-term application given the current level of technology of electric propulsion". Current operational uses of electric propulsion include on-orbit maneuvers such as stationkeeping and drag make-up. A potential current or near-term application of electric propulsion involves GEO orbit circularization in the case of the chemical apogee engine failure. Geosynchronous spacecraft are usually injected into an elliptical geosynchronous transfer orbit (GTO) with an apogee at GEO altitude and a perigee at LEO altitude. In 1989, the GSTAR-3 satellite utilized the hydrazine resistojet engine designed for on-orbit station-keeping to circularize the GTO after the apogee engine failed".

In this appendix, the use of a combined chemical/electric propulsion system for a LEOGEO transfer is investigated. The proposed mission scenario involves a chemical insertion into GTO, followed by a chemical apogee burn to partially raise perigee and rectuce inclination. and finally a low-thrust orbit transfer to equatorial GEO. The objective is to obtain the optimal propulsion modes which maximize the spacecraft's payload in GEO and to compare this optimal combined chemical/electric propulsion strategy to an all-chemical propulsion LEO-GEO transfer.

\section{MISSION AND SPACECRAFT DEFINITION}

\section{LEO.GEO Mission}

For this study, the spacecraft is assumed to be injected into GTO by an Atlas 2AS launch vehicle. The resulting elliptical transfer orbit has a perigee altitude of $167 \mathrm{~km}$. an apogee altitude of $35.786 \mathrm{~km}$ (GEO), and an inclination of 26.5 degrees. Total spacecraft mass in GTO after the perigee bum is $3833 \mathrm{~kg}$. The apogee chemical thruster is a bipropellant system with a specific impulse $\left(I_{s p}\right)$ of $314 \mathrm{~s}$. Arcjet thrusters are used for the electric propulsion system since they have been identified as a good candidate for the dual role of station-keeping and primary propulsion ${ }^{5}$. The arcjet propulsion system has a total input power of $7.5 \mathrm{~kW}$, an $I_{s p}$ of $600 \mathrm{~s}$, and an engine efficiency of $32 \%$. Therefore, the resulting thrust magnitude is $0.815 \mathrm{~N}$ and the constant propellant mass flow rate is $11.97 \mathrm{~kg} /$ day. The solar arrays are assumed to have a equivalent layer of $12 \mathrm{mils}$ silica shieding on both sides for radiation protection. The arcjet engines are also to be utilized for GEO station-keeping.

\section{Spacecraft Mass Analysis}

The total mass $m_{\text {oro }}$ of a spacecraft with chemical and electric stages after insertion into GTO is

$\mathrm{m}_{\mathrm{GTO}}=\mathrm{m}_{\mathrm{pc}}+\mathrm{m}_{\mathrm{dryc}}+\mathrm{m}_{\mathrm{pe}}+\mathrm{m}_{\text {tanke }}+\mathrm{m}_{\mathrm{pp}}+\mathrm{m}_{\text {net }}$

where $m_{p c}$ is the propellant mass, $m_{d y c}$ is the dry mass of the chemical stage, $m_{\text {tanke }}$ is the tank mass of the electric stage, $m_{p p}$ is the power and propulsion system mass of the electric stage, and $\mathrm{m}_{\text {net }}$ is the net mass. The spacecraft's net mass represents the usable mass for payload plus the basic spacecraft structural mass. The subscripts $c$ and $e$ represent the chemical and electric propulsion stages, respectively. The injected mass $\mathrm{m}_{\mathrm{GTO}}=3833 \mathrm{~kg}$ represents the launch capability of the Atlas $2 A S$ vehicle. The propellant masses $\mathrm{m}_{\mathrm{pc}}$ and $\mathrm{m}_{\mathrm{pe}}$ are calculated from the rocket equation

$$
m_{p}=m_{i}\left(1-e^{-\Delta V / g \text { Isp }}\right)
$$

where $\mathrm{m}_{\mathrm{i}}$ is the initial mass prior to the respective propulsive maneuver, $\Delta \mathrm{V}$ is the 
velocity change. $g$ is the gravitational acceleration at sea-level. and $I_{s p}$ is the specific impulse of the respective propulsion stage. The dry mass $m_{\text {dryc }}$ includes the structural, engine, and tank mass of the chemical stage and is assumed to be $12 \%$ of the chemical propellant mass ". Tank mass $m_{\text {tanke }}$ is $8 \%$ of the propellant for the electric stage ${ }^{4}$. Power and propulsion system mass of the electric stage $m_{p p}$ is the product of electric input power $P$ and specific mass $\alpha$. Specific mass for a power and propulsion system comprised of Galium Arsenide solar array cells and arcjet thrusters is fixed at 30 $\mathrm{kg} / \mathrm{kW}$ which results in $m_{\mathrm{pp}}=225 \mathrm{~kg}$.

\section{MISSION ANALYSIS}

The net mass $m_{\text {net }}$ can be expressed using equation(1) and the previous mass definitions as

$\mathrm{m}_{\text {net }}=\mathrm{m}_{\mathrm{GTO}}-1.12 \mathrm{~m}_{\mathrm{pc}}-1.08 \mathrm{~m}_{\mathrm{pe}}-\mathrm{m}_{\mathrm{pp}}$

Since the launch vehicle capability and electric power and propulsion system are both considered to be fixed, $m_{G T O}$ and $m_{p p}$ are constants. Therefore, in order to maximize $m_{n e t}$, the optimal combination of propellant for the chemical and electric stages must be determined. In other words, we must find what portion of the three-dimensional, GTO-GEO transfer is performed initially by a chemical GTO apogee burn and how the remaining portion of the transfer is completed by electric propulsion such that $m_{n e t}$ is maximized.

This problem is solved by parametrically varying the magnitude and orientation of the chemical GTO apogee burns in order to produce a range of intermediate inclined elliptical orbits. These intermediate orbits provide initial conditions for the subsequent low-thrust transfers to equatorial GEO. Table I presents a range of chemical GTO apogee burns designed to raise perigee and rocuce inclination. Four discrete perigee $\Delta r_{p}$ and four discrete inclination reductions $\Delta i$ are produced by the respective velocity changes $\Delta \mathrm{V}$ and out-ofplane thrust pointing angles $\psi$ as indicated in Table 1. The impulsive chemical apogee burn is assumed to have components along the apogee velocity vector and normal to the original GTO plane. The pointing angle $\psi$ is measured from the GTO plane to the impulsive thrust vector. Table $l$ also presents the propellant mass $m_{p c}$ and orbital elements semi-major axis a. eccentricity $e$, and inclination $i$ of the intermediate orbits as a result of the apogee burn. Case 1 corresponds to the absence of an apogee burn and Case 16 corresponds to a complete GTO-GEO transfer via the chemical apogee bum.

Next, the optimal minimum-fuel. low thrust transfers from the initial conditions presented in Table 1 to equatorial GEO are obtained. These minimum-fuel transfer problems are solved by the low-thrist trajectory optimization program SECKSPOT which utilizes an indirect optimization method and solves the two-point boundary value problem via a multiple-shooting method ${ }^{7}$. SECKSPOT uses orbital averaging for the governing equations of motion and simulates Earth-shadow effects, Earth oblateness, and solar cell degradation due to the radiation belts. Once the minimum-fuel transfer to GEO is computed. the additional propellant required by the electric stage for station-keeping is calculated using equation (2). A total annual $\Delta \mathrm{V}$ budget of 50 $\mathrm{m} / \mathrm{s}$ for East-West and North-South stationkeeping over a spacecraft lifetime of 10 years is assumed ${ }^{4}$.

\section{RESULTS}

The resulting payload fractions $\mathrm{m}_{\text {net }} / \mathrm{m}_{\text {GTo }}$ for the sixteen parametric cases are outlined by Table 1. Clearly, the propulsion strategy for maximum net mass in GEO is the all electric propulsion GTO-GEO transfer without the use of a chemical apogee rocket. The resulting maximum payload fraction is 0.498 for the allelectric propulsion transfer compared to 0.397 for the all-chemical propulsion transfer. Therefore, the all-electric transfer demonstrates a $25.4 \%$ increase in payload over the all-chemical transfer. Table 1 aiso indicates that if the entire plane change is performed by a chemical apogee burn. then the payload fraction is essentially the same for the variety of combined chemical/electric propulsion maneuvers for perigee raise. Both strategies show a total initial mass of $3833 \mathrm{~kg}$ in GTO and the all-electric propulsion case shows a clear increase in net mass. 
The resulting low-thrust orbit transter time. subsequent power degradation and final spacecraft mass and net mass in GEO for each of the 16 cases detailed in Table 1 is presented in Table 2.

The low-thrust transfer time is highest at 121 days for the all-electric propulsion transfer and is lowest at 14.8 days for Case 12. It is interesting to note that the net mass is increased $104.4 \mathrm{~kg}$ over the all-chemical propulsion transfer as indicated by Case 7 in Table 2. The corresponding low-thrust transfer time for this case is 45.9 days which may be considered to be a good trade between total trip time. power degradation, and payload mass increase. Solar cell degradation due to time spent traversing the radiation belt is calculated by SECKSPOT as a percentage loss of the available power at the beginning of the mission. Power degradation is worst at about $5.5 \%$ for Cases $1-4$ which do not employ a perigee raise via the chemical apogee burn. Power degradation decreases as perigee is raised by the apogee bum but remains less than $1 \%$ for Cases 5-16. The total transfer time and power loss is significantly less than the corresponding all-electric propulsion orbit transfer from LEO to GEO.

\section{CONCLUSIONS}

A maximum payload problem for a LEO-GEO transfer using a combined chemical/electric propulsion system has been formulated and solved. The problem is solved by parametrically varying the magnitude and direction of the chemical GTO apogee burn and solving the subsequent electric propulsion transfers with a low-thrust trajectory optimization code. The payload is maximized when the entire GTO-GEO transfer is performed by the electric propulsion stage and the optimal transfer requires 121 days with a $5.2 \%$ loss in solar power. An additional $104 \mathrm{~kg}$ in payload for a transfer time of 46 days can be realized if the GTO-GEO transfer is performed with both chemical and electric propulsion. The optimal combined chemicalelectric propulsion LEO-GEO mission can provide an additional $25.4 \%$ payload capability compared to the corresponding allchemical LEO-GEO mission.

\section{REFERENCES}

A1. Y. Matogawa, Optimum Low Thrust Transfer to Geosynchronous Orbit. Acta Astronautica. 467-478 (1983).

A2. R.L. Burton and C. Wassgren. Time-Critical Low-Thrust Orbit Transfer Optimization.

Joumal of Spacecrafi and Rockets.

286-288 (1992).

A3. J.M. Spondable and J.P. Penn, Electric Propulsion for Orbit Transfer. A Case Study Journal of Propulsion and Power. 445-451 (1989).

A4. S.W. Janson, "The On-Orbit Role of Electric Propulsion.” AIAA Paper 93-2220, 29th Joint Propulsion Conf., Monterey, California (1993).

A5. M. Andrenucci, G. Baiocchi. W. Deininger and A. Trippi, DIVA: Flight Demonstration of a $1 \mathrm{~kW}$ Arcjet Propulsion System.

Space Technology. 25-32 (1993).

A6. B. Palaszewski, Lunar Missions Using Advanced Chemical Propulsion: System Design Issues.Journal of Spacecraft and Rockets.: 458-465 (1994).

A7. L.L. Sackett, H.L. Malchow and T.N. Edelbaum, Solar Electric Geocentric Transfer with Attitude Constraints: Analysis. NASA CR134927. C.S. Draper Laboratories (1975). 
Table 1:Chemical apogee burns and resulting intermediate orbits

\begin{tabular}{cccccccccc}
\hline Case & $\Delta \mathrm{V}$ & $\psi$ & $\mathrm{m}_{\mathrm{pc}}$ & $\Delta \mathrm{r}_{\mathrm{p}}$ & $\Delta \mathrm{i}$ & $\mathrm{a}$ & $\mathrm{e}$ & $\mathrm{I}$ \\
\cline { 3 - 7 } & $(\mathrm{m} / \mathrm{s})$ & $(\mathrm{deg})$ & $(\mathrm{kg})$ & $(\mathrm{km})$ & $(\mathrm{deg})$ & $(\mathrm{km})$ & & $(\mathrm{deg})$ \\
1 & 0 & - & 0.0 & 0 & 0.0 & 24,355 & 0.731 & 26.5 \\
2 & 245.4 & 94.42 & 293.6 & 0 & 8.83 & 24,355 & 0.731 & 17.67 \\
3 & 489.6 & 98.84 & 563.5 & 0 & 17.67 & 24,355 & 0.731 & 8.83 \\
4 & 730.7 & 103.25 & 809.6 & 0 & 26.5 & 24,355 & 0.731 & 0.0 \\
5 & 803.6 & 0.0 & 880.4 & 11,873 & 0.0 & 30,291 & 0.392 & 26.5 \\
6 & 858.1 & 25.40 & 932.2 & 11,873 & 8.83 & 30,291 & 0.392 & 17.67 \\
7 & 1003.2 & 46.50 & 1065.7 & 11,873 & 17.67 & 30,291 & 0.392 & 8.83 \\
8 & 1203.7 & 62.72 & 1240.1 & 11,873 & 26.5 & 30,291 & 0.392 & 0.0 \\
9 & 1217.6 & 0.0 & 1251.8 & 23,746 & 0.0 & 36,228 & 0.164 & 26.5 \\
10 & 1260.4 & 20.02 & 1287.5 & 23,746 & 8.83 & 36,228 & 0.164 & 17.67 \\
11 & 1380.3 & 38.19 & 1384.7 & 23,746 & 17.67 & 36,228 & 0.164 & 8.83 \\
12 & 1557.0 & 53.68 & 1521.2 & 23,746 & 26.5 & 36,228 & 0.164 & 0.0 \\
13 & 1480.7 & 0.0 & 1463.3 & 35,619 & 0.0 & 42,164 & 0.0 & 26.5 \\
14 & 1519.5 & 18.10 & 1492.9 & 35,619 & 8.83 & 42,164 & 0.0 & 17.67 \\
15 & 1629.4 & 34.94 & 1575.0 & 35,619 & 17.67 & 42,164 & 0.0 & 8.83 \\
16 & 1795.1 & 49.84 & 1693.3 & 35,619 & 26.5 & 42,164 & 0.0 & 0.0 \\
\hline
\end{tabular}

Table 2: GTO-GEO transfers

\begin{tabular}{ccccc}
\hline Case & Low-thrust transfer & Power degradation & $\mathrm{m}_{\text {GEO }}$ & $\mathrm{m}_{\text {gef }}$ \\
\hline \hline $\mathbf{1}$ & (days) & $(\%)$ & $\mathbf{( k g )}$ & $(\mathrm{kg})$ \\
2 & $\mathbf{1 2 1 . 0}$ & $\mathbf{5 . 2 2}$ & $\mathbf{2 , 4 5 8 . 9}$ & $\mathbf{1 , 9 0 7 . 7}$ \\
3 & 104.4 & 5.56 & $2,360.0$ & $1,797.8$ \\
4 & 91.3 & 5.57 & $2,236.3$ & $1,664.3$ \\
5 & 82.6 & 5.57 & $2,086.4$ & $1,505.8$ \\
6 & 79.0 & 0.77 & $2,013.4$ & $1,430.5$ \\
7 & 62.3 & 0.74 & $2,157.7$ & $1,571.6$ \\
8 & $\mathbf{4 5 . 9}$ & $\mathbf{0 . 6 3}$ & $\mathbf{2 , 2 1 9 . 6}$ & $\mathbf{1 , 6 2 7 . 7}$ \\
9 & 37.9 & 0.53 & $2,140.2$ & $1,541.9$ \\
10 & 67.5 & 0.40 & $1,774.2$ & $1,178.4$ \\
11 & 49.0 & 0.42 & $1,960.0$ & $1,361.3$ \\
12 & 27.7 & 0.33 & $2,117.1$ & $1,513.2$ \\
13 & 14.8 & 0.19 & $2,134.2$ & $1,524.7$ \\
14 & 60.8 & 0.11 & $1,641.6$ & $1,038.4$ \\
15 & 43.1 & 0.15 & $1,824.2$ & $1,218.3$ \\
$\mathbf{1 6}$ & 22.3 & 0.13 & $1,990.8$ & $1,380.3$ \\
\hline
\end{tabular}


Public reporting burden for this collection of information is estimated to average 1 hour per response, including the time for reviewing instructions, searching existing data sources, gathering and maintaining the data needed, and completing and reviewing the collection of information. Send comments regarding this burden estimate or any other aspect of this collection of information, including suggestions for reducing this burden, to Washington Headquarters Services, Directorate for Intormation Operations and Reports, 1215 Jefterson Davis Highway. Suite 1204, Arlington, VA 22202-4302, and to the Otlice of Management and Budget, Papenwork Reduction Project (0704-0188), Washington, DC 20503.

\begin{tabular}{|l|l|l}
\hline 1. AGENCY USE ONLY (Leave blank) & $\begin{array}{c}\text { 2. REPORT DATE } \\
\text { August } 1995\end{array}$ & $\begin{array}{r}\text { 3. REPORT TYPE AND DATES COVERED } \\
\text { Technical Memorandum }\end{array}$ \\
\hline
\end{tabular}

\section{TITLE AND SUBTTILE}

5. FUNDING NUMBERS

Advanced Propulsion for Geostationary Orbit Insertion and

North-South Station Keeping

6. AUTHOR(S)

Steven R. Oleson, Roger M. Myers, Craig A. Kluever, John P. Riehl and

WU-564-09-20

Francis M. Curran

NAS3-27186

\section{PERFORMING ORGANIZATION NAME(S) AND ADDRESS(ES)}

8. PERFORMING ORGANIZATION REPORT NUMBER

National Aeronautics and Space Administration

Lewis Research Center

Cleveland, Ohio 44135-3191

E-9818

9. SPONSORING/MONITORING AGENCY NAME(S) AND ADDRESS(ES)

10. SPONSORINGMONITORING AGENCY REPORT NUMBER

National Aeronautics and Space Administration

Washington, D.C. 20546-0001

NASA TM-107018

AIAA-95-2513

11. SUPPLEMENTARY NOTES

Prepared for the 31 st Joint Propulsion Conference and Exhibit cosponsored by AIAA, ASME, SAE and ASEE, San Diego, California, July 10-12, 1995. Steven R. Oleson and Roger M. Myers, NYMA Inc., 2001 Aerospace Parkway, Brook Park, Ohio 44142 (work funded by NASA Contract NAS327186); Craig A. Kluever, University of Missouri-Columbia/Kansas City, Kansas City, Missouri; John P. Riehl and Francis M. Curran, NASA Lewis Research Center. Responsible person, John P. Riehl, organization code 6820, (216) 433-7061.

12a. DISTRIBUTIONAVAILABILITY STATEMENT

12b. DISTRIBUTION CODE

Unclassified -Unlimited

Subject Categories 13, 15, 16 and 20

This publication is available from the NASA Center for Aerospace Information, (301) 621-0390.

13. ABSTRACT (Maximum 200 words)

Solar Electric Propulsion (SEP) technology is currently being used for geostationary satellite station keeping to increase payload mass. Analyses show that advanced electric propulsion technologies can be used to obtain additional increases in payload mass by using these same technologies to perform part of the orbit transfer. In this work three electric propulsion technologies are examined at two power levels for an Atlas IIAS class spacecraft. The on-board chemical propulsion apogee engine fuel is reduced in this analysis to allow the use of electric propulsion. A numerical optimizer is used to determine the chemical burns which will minimize the electric propulsion transfer time. Results show that for a $1500 \mathrm{~kg}$ Atlas IIAS class payload, increases in net mass (geostationary satellite mass less wet propulsion system mass) of 100 to $800 \mathrm{~kg}$ are possible using electric propulsion for station keeping, advanced chemical engines for part of the transfer and electric propulsion for the remainder of the transfer. Trip times are between one and four months.

14. SUBJECT TERMS

GEO; Geostationary; Geosynchronous; Orbit insertion; Electric propulsion; Station keeping; On-Board chemical propulsion

17. SECURITY CLASSIFICATION OF REPORT Unclassified
18. SECURTYY CLASSIFICATION OF THIS PAGE Unclassified
19. SECURITY CLASSIFICATION OF ABSTRACT Unclassified 
National Aeronautics and

Space Administration

\section{Lewis Research Center}

21000 Brookpark Rd.

Cleveland, $\mathrm{OH}$ 44135-3191

Officlal Business

Penalty for Private Use $\$ 300$

POSTMASTER: If Undeliverable - Do Not Return
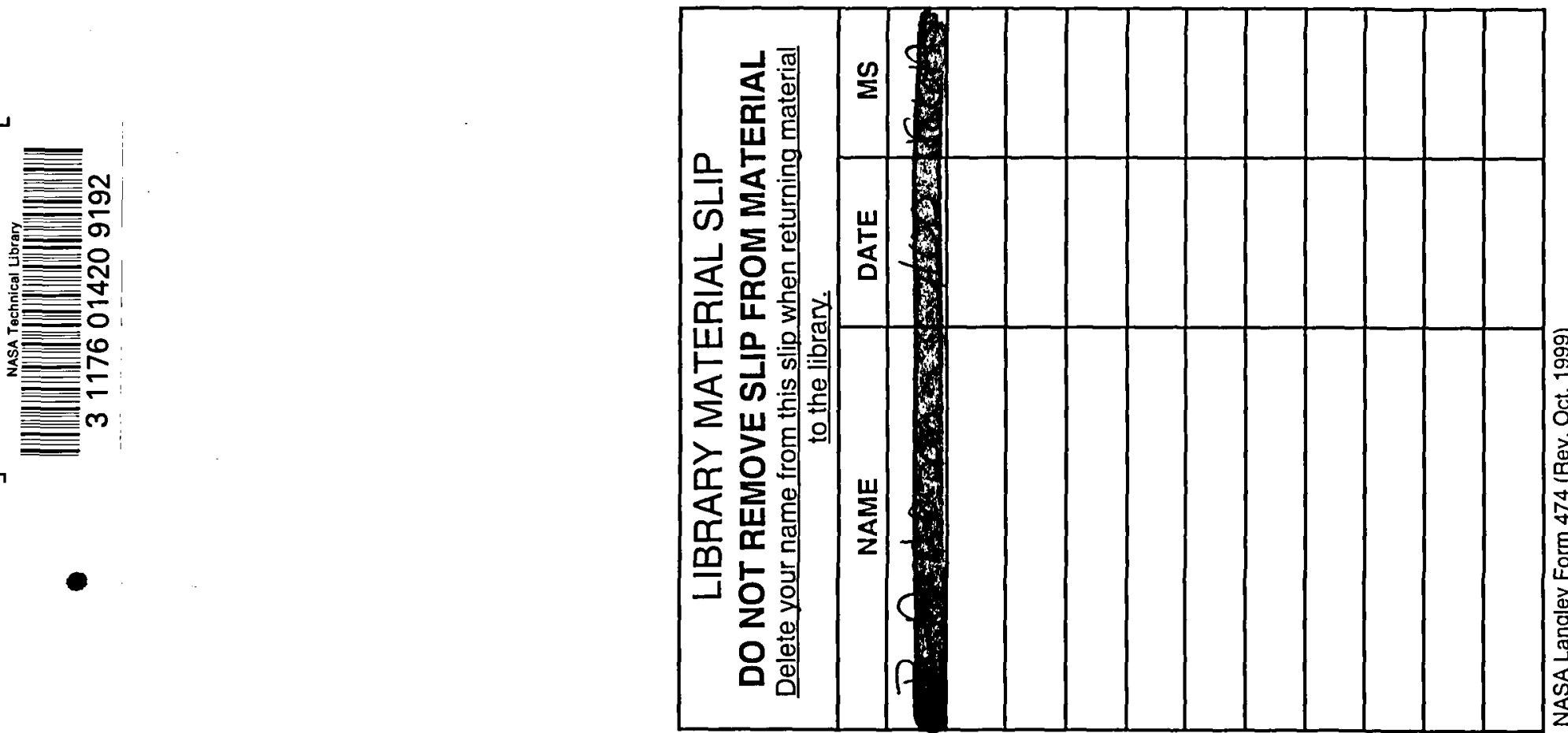